\title{
Peroxidase Inhibition and Antioxidant Activity of Bulk-Marketed Black Tea (Camellia sinensis L.) from the Democratic Republic of the Congo
}

\author{
Nadege Ngombe Kabamba1 ${ }^{*}$, Joyce Mbuyi Katalayi ${ }^{*}$, Jimmy Kabeya Kabengele ${ }^{1}$, \\ Grâce Nkakapen Djoumbissi' ${ }^{1}$, Marie Joe Kabongo Kapinga ${ }^{1}$, Théophile Mbemba Fundu², \\ Dieudonné Tshitenge Tshitenge ${ }^{1}$, Pascal Dibungi T. Kalenda ${ }^{1}$, Paulin Mutwale Kapepula1\# ${ }^{10}$ \\ ${ }^{1}$ Centre d'Etudes des Substances Naturelles d'Origine Végétale (CESNOV), Faculty of Pharmaceutical Sciences, University of \\ Kinshasa, Kinshasa, The Democratic Republic of the Congo \\ ${ }^{2}$ Laboratoire d'Analyses et de Recherche en Alimentation et Nutrition (LARAN), Department of Biology, Faculty of Sciences, \\ University of Kinshasa, Kinshasa, The Democratic Republic of the Congo \\ Email: "garaphmutwal@yahoo.fr
}

How to cite this paper: Kabamba, N.N., Katalayi, J.M., Kabengele, J.K., Djoumbissi, G.N., Kapinga, M.J.K.., Fundu, T.M., Tshitenge, D.T., Kalenda, P.D.T., Kapepula, P.M. (2019) Peroxidase Inhibition and Antioxidant Activity of Bulk-Marketed Black Tea (Camellia sinensis L.) from the Democratic Republic of the Congo. Journal of Biosciences and Medicines, 7, 66-80. https://doi.org/10.4236/jbm.2019.79007

Received: August 16, 2019

Accepted: September 7, 2019

Published: September 10, 2019

Copyright $\odot 2019$ by author(s) and Scientific Research Publishing Inc. This work is licensed under the Creative Commons Attribution International License (CC BY 4.0).

http://creativecommons.org/licenses/by/4.0/ (c) (i) Open Access

\begin{abstract}
The widely known leaves of Camellia sinensis (L.) derive the most consumed beverage globally. All over the world, like in the Democratic Republic of the Congo (DR Congo), they are marketed in the form of packaged and in bulk black tea. The aim of this study was to report the microscopic botanical features, the chromatographic fingerprints, the antioxidant activities, and the peroxidase inhibition of bulk-marketed black teas consumed in DR Congo. The microscopic analysis of powders from unpackaged black tea marketed in DR Congo allowed the identification of specific microscopical features, which are characteristic to $C$. sinensis (L.) such as numerous asterosclerites, numerous fragments of unicellular trichomes; fragments of abaxial epidermis consisting of cells with slightly wavy walls, numerous anomocytic stomata, and the detection of biological contaminants, e.g. the dust mites. TLC and HPLC analysis indicated that flavonoids (hyperoside, rutin) and phenolic acids (chlorogenic acid, gallic acid) were major phenolic compounds, along with other secondary metabolites. Aqueous extracts from all bulk-marketed black teas exhibited good antioxidant activities at the concentrations range of $1-20 \mu \mathrm{g} \cdot \mathrm{mL}^{-1}$ using in vitro ABTS and DPPH assays. These extracts showed equally inhibitory effects on myeloperoxidase (MPO) and horseradish peroxidase (HRP) activities at the concentration ranges of $1-20 \mu \mathrm{g} \cdot \mathrm{mL}^{-1}$ and $20-$ $100 \mu \mathrm{g} \cdot \mathrm{mL}^{-1}$ respectively. Bulk-marketed black teas consumed in DR Congo possess antioxidant and anti-inflammatory properties comparable to packaged Ceylon tea largely marketed. The observed bioactivities support the
\end{abstract}

*These authors contributed equally to this article. 
health benefits of the consumed black tea by Congolese people, despite the storage conditions to be improved in order to preserve its nutritional and therapeutic assets.

\section{Keywords}

Antioxidant Activity, Black Tea, Camellia sinensis, HRP, L-012, Mites, Myeloperoxidase

\section{Introduction}

Camellia sinensis (L.) grows best in some tropical and subtropical country such as the Democratic Republic of the Congo (DR Congo) [1]. Tea is a popular beverage worldwide [2] [3]. There are four main types of tea produced from this same plant, depending on how the tea leaves are processed such as the degree of fermentation, taste, and color. Tea is generally consumed in the forms of green, Oolong, Puerh, and black tea, all of which originate from the leaves of the plant C. sinensis (L.) [3] [4]. Oolong tea is very common in many countries; however, green tea is preferred over the other types in China and Japan. Black tea is prevalent among Western countries and dominates the market economically [5]. Tea is valued for its taste, aroma, health benefits, and cultural practices [6]. In the Democratic Republic of the Congo (DR Congo), black tea is largely consumed during breakfast such as a popular drink by Congolese population. Packaged and bulk-marketed black teas are marketed under various trade names presented such as having high quality nutritional and therapeutic values. Increasingly the Congolese population gives more preference to packaged teas at the expense of bulk-marketed black teas for quality reasons. The aim of this study was to evaluate the antioxidant activity and the inhibition effect on peroxidases (HRP and MPO) of infusion from bulk-marketed black tea consumed in the Congo. Additionally, to better characterize the different teas investigated, their microscopical characteristics and their chromatographic fingerprints were determined.

\section{Materiel and Methods}

\subsection{Tea Samples}

This study was conducted during 2018 to Kinshasa in DR Congo. The bulk-marketed black teas were collected from two markets of Kinshasa (La Liberté and Zikida) (Table 1). They were finely ground in a high-speed mill (Retsch ZM 100 Model) and sieved at $180 \mu \mathrm{m}$ particle size.

\subsection{Chemicals and Reagents}

All solvents used were of analytical and HPLC grade and purchased from Merck VWR (Leuven, Belgium). 2-Aminoethyldiphenylborat and vanillin were purchased from Sigma (Bornem, Belgium). L-012 (8-amino-5-chloro-7-phenylpyrido 
Table 1. List of studied bulk-marketed black teas marketed in DR Congo.

\begin{tabular}{cccc}
\hline Samples & Trade Names & Origines & Markets \\
\hline Tea 1 & Manyuka jaune & Bukavu/DRC & La liberté \\
Tea 2 & PF1 & Ouganda & La liberté \\
Tea 3 & BM manyuka & Bukavu/DRC & La liberté \\
Tea 4 & Rabbata & Bukavu/DRC & La liberté \\
Tea 5 & PF & Ouganda & La liberté \\
Tea 6 & Albona & Bukavu/DRC & Zikida \\
Tea 7 & Lipton 1 & Bukavu/DRC & Zikida \\
Tea 8 & Phoenix & Bukavu/DRC & Zikida \\
Tea 9 & Lipton 2 ouganda & Ouganda & Zikida \\
Tea 10 & Manyuka & Bukavu/DRC & Zikida \\
Tea TB & LEBEST (Figure 1$)$ & Ceylon & Shop Unikin \\
\hline
\end{tabular}

$\left.{ }^{*}\right)$ LEBEST is a packaged black tea $(2 \mathrm{~g} /$ tea bag $)$ from Ceylon used such as reference tea or standard tea.

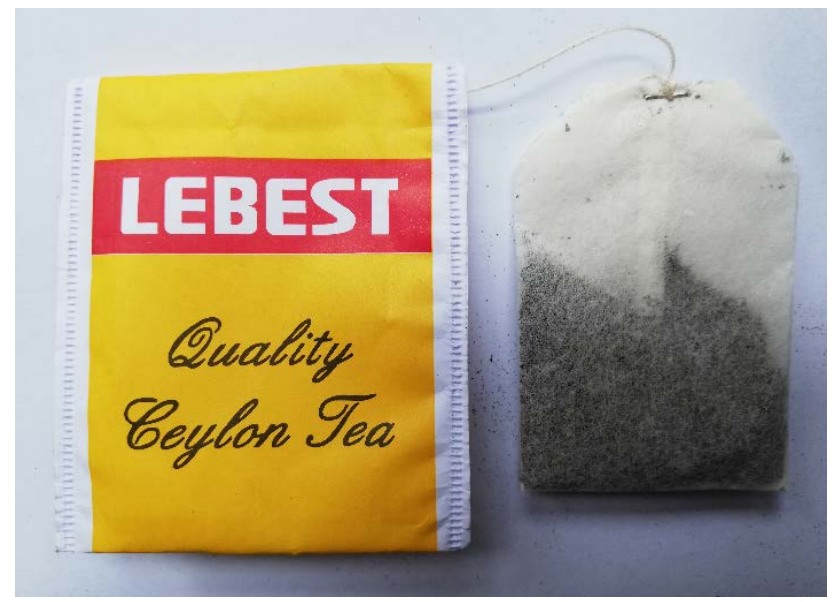

Figure 1. Packaged tea "LEBEST".

[3,4-d]pyridazine- $1,4(2 \mathrm{H}, 3 \mathrm{H})$ dione) was purchased from Wako Chemicals GmbH (Neuss, Germany).

Horseradish peroxidase (HRP) was obtained from Roche (Mannheim, Germany) and human Myeloperoxidase was from Calbiochem, EMD Millipore (Bellirica, MA, USA). Caffeic acid (purity 96\%), gallic acid (purity: 97\%) was purchased from Sigma-Aldrich. Rutin (purity $\geq 99 \%$ ), isoquercitrin (purity $\geq 99 \%$ ) and, hyperoside (purity $\geq 98 \%$ ) were HPLC grade and purchased from Extrasynthese. Water was treated using a Milli-Q water ultra-purification system before use.

\subsection{Microscopic Analysis}

Powder observations were made using lactic acid reagent (European Pharmacopeia reagent) [7]. For the microscopic analysis, two drops of lactic acid reagent 
dropped on the slide were mixed with a small quantity of powder and then covered with a cover glass. The obtained microscopic preparation was warmed up to boiling. Observations were made with a Zeiss Primo Star 200 microscope and pictures were taken with Smart Phone Samsung E7.

\subsection{Preparation of Extracts}

Aqueous extracts were prepared by infusion of $10 \mathrm{~g}$ of sample powders with 100 $\mathrm{mL}$ of water for 10 minutes. The infusion was cooled to room temperature before filtration and the evaporation of the solvent was performed by lyophilisation (a Christ Alpha 1-4 LSC ${ }^{\oplus}$ apparatus). The extracts were then weighed and kept in dark hermetic flasks at $4^{\circ} \mathrm{C}$.

\subsection{Phytochemical Analysis}

\subsubsection{Thin Layer Chromatography (TLC) Analysis}

Analytical TLC of $10 \mu \mathrm{L}$ of solution for $10 \mathrm{mg} \cdot \mathrm{mL}^{-1}$ of methanolic and dichloromethane extracts was carried out on normal phase Silica gel $60 \mathrm{~F}_{254}$ plates (Merck), using different eluents for the identification of secondary metabolites [8]. TLC of $10 \mu \mathrm{L}$ of methanolic solutions was carried out on Silica gel $60 \mathrm{~F}_{254}$ plates (Merck), using ethyl acetate/formic acid/ methanol/water (20:0.5:2.5:2; $\mathrm{v} / \mathrm{v} / \mathrm{v} / \mathrm{v}$ ) as eluent. Caffeic acid, chlorogenic acid, ferulic acid, hyperoside, astragalin, isoquercitrin and rutin were used as a standards. The plate was sprayed with Natural Products-PEG reagent and observed at UV-365 nm.

\subsubsection{High-Performance Liquid Chromatography (HPLC) Analysis and Purification}

Analytical separation on HPLC-DAD was carried out on a Hypersil ODS ${ }^{\circledast}$ RP18 column as described previously [9]. The analysis was carried out at $25^{\circ} \mathrm{C}$ by an "Agilent 1100" HPLC chain connected to a diode array detector (DAD). All samples and standards were filtered through a $0.45 \mu \mathrm{m}$ pore size syringe-driven filter before $20 \mu \mathrm{L}$ of each one were injected into the HPLC-UV/DAD system. The separation was carried out using an Hypersil ODS column $(4 \times 250 \mathrm{~mm})$ with a nonlinear gradient of acetonitril (solvent $\mathrm{A}$ ) and $0.05 \%$ trifluoroacetic acid in ultra pure water (solvent $B$ ) in the following composition: $0 \mathrm{~min}, 0: 100$ (A:B), 1 min, 3:97 (A:B); 45 min, 40:60 (A:B); 55 min, 40:60 (A:B); 56 min, 0:100 $(\mathrm{A}: \mathrm{B})$ and $60 \mathrm{~min}$, stop. The time $(\mathrm{T})$ is expressed in minutes. The compounds were eluted at a flow rate of $1 \mathrm{~mL} / \mathrm{min}$ and detected with UV-DAD. The UV spectra of elution peaks were recorded in the range from 250 to $340 \mathrm{~nm}$ and the chromatograms were monitored at 280 and $340 \mathrm{~nm}$. The identification was based on the retention time and the absorption spectra in comparison to the references.

\subsubsection{Phytochemical Contents}

Total phenolic, flavonoid and anthocyanin contents were determined by methods described previously [7] [10]. 


\subsection{Cellular Free and Enzymatic Assays}

The extracts were solubilized in water, thus their effect was compared to a control test performed with water alone.

\subsubsection{Cellular Free Antioxidant Activity}

In vitro antioxidant analysis was performed by ABTS and DPPH assays as described previously [10] [11].

\subsubsection{Peroxidase Inhibitions}

\section{1) Inhibition of Myeloperoxidase Activity}

PBS solutions of the plant extracts to the final concentrations of $0.1,1$ and 10 $\mu \mathrm{g} \cdot \mathrm{mL}^{-1}$ were incubated for $10 \mathrm{~min}$ with $\mathrm{MPO}$ at a final concentration of 25 $\mathrm{ng} \cdot \mathrm{mL}^{-1}$. After incubation, $100 \mu \mathrm{L}$ of the mixtures were loaded into the 96-well microtitration plates and incubated for 10 minutes at $37^{\circ} \mathrm{C}$ in darkness. The MPO peroxidase activity (enzymatic activity) was detected by adding $100 \mu \mathrm{L}$ of Amplex ${ }^{\oplus}$ Red solution $(80 \mu \mathrm{M})$ solution dissolved in phosphate buffer $(50 \mathrm{mM}$, at $\mathrm{pH}$ 7.5), $\mathrm{H}_{2} \mathrm{O}_{2}(10 \mu \mathrm{M})$ and $10 \mu \mathrm{L}$ sodium nitrite $(10 \mathrm{mM})$. The oxidation of Amplex ${ }^{\oplus}$ Red into the fluorescent adduct resorufin $(\lambda$ excitation $=544 \mathrm{~nm} ; \lambda$ emission $=590 \mathrm{~nm}$ ) was monitored for $30 \mathrm{~min}$ at $37^{\circ} \mathrm{C}$ with a fluorescent plate reader (Fluoroskan Ascent, Fisher Scientific). A control assay set as 100\% MPO activity was performed with purified MPO in the presence of PBS instead of the plant extracts [12].

\section{2) Inhibition of HRP Oxidant (or Oxidative) Activity}

This method evaluates the modulatory effect of extracts on HRP catalytic activity using L-012, a luminol-based chemiluminescent probe. Two microliters of extract solutions at final concentrations of $0.1,1$ and $10 \mu \mathrm{g} \cdot \mathrm{mL}^{-1}$ were added to $163 \mu \mathrm{L}$ of Phosphate buffer, $5 \mu \mathrm{L}$ of HRP $\left(1 \mathrm{mg} \cdot \mathrm{mL}^{-1}\right), 10 \mu \mathrm{L}$ of L-012 and $20 \mu \mathrm{L}$ of $\mathrm{H}_{2} \mathrm{O}_{2}$. In each assay, three wells were loaded without plant extracts but with DMSO and were taken as control (100\% CL response). To measure the basic CL response at the absence of activation, three other wells without plant extract did not receive $\mathrm{H}_{2} \mathrm{O}_{2}$ (NA, not activated). The CL response was monitored for 30 minutes at $37^{\circ} \mathrm{C}$ with a Fluoroscan Ascent spectrophotometer (Fisher Scientific, Tournai, Belgium) and expressed as the integral value of the total CL emission [10].

\subsection{Statistical Analysis}

Each concentration was tested in triplicate in each assay, and at least three different assays were performed. All results were expressed as mean values \pm standard deviation (SD). The statistical analysis was performed with GraphPad 7.0 (GraphPad Software, San Diego California, USA). Two-way ANOVA was used; multiple comparisons of all data were performed using the "Tukey" Multiple Comparisons Test and the level of statistical significance was set at $\mathrm{p}<0.05$. The $\mathrm{IC}_{50}$ values were calculated with GraphPad Prism 7.0 under application of the function "log (inhibitor) vs. normalized response-variable slope" after convert- 
ing the concentrations into their decimal logarithm.

\section{Results and Discussion}

\subsection{Botanical Features}

Examined under a microscope using European Pharmacopeia reagent (Lactic acid reagent), the powders of different samples showed the following diagnostic characters: numerous asterosclerites (Figure 2), numerous fragments of unicellular trichomes; fragments of abaxial epidermis consisting of cells with slightly wavy walls, numerous anomocytic stomata, slightly thickened walls, accompanied by cells of the underlying palisade parenchyma; numerous isolated and grouped sclereids (Figure 3), palisade parenchyma usually arranged in 2 layers, spongy parenchyma including cells containing cluster crystals of calcium oxalate; fragments of spiral vessels accompanied by lignified fibers. Numerous starch grains, drop oils were also identified. Microscopy analysis showed equally foreign elements such as insect pests (mites) and grain of sand in three samples (Figure 4).

The detection, prevention and eradication of mites and insects infestation is an important hygienic and economic consideration for natural products. The presence of mites or insects in studied black teas is critical for quality of teas consumed by the Congolese population. Bulk-marketed black teas are conserved in the woven sacks and are sold outdoors in the large plastic basin. Storage conditions affect the quality of tea products. The main factors influencing tea quality and polyphenol stability during storage are light, oxygen, and temperature [6]. Weather conditions to Kinshasa (DR Congo), are characterized by high temperatures and high humidity. Effective preventive measures of natural products involve good hygiene in the warehouse (removal of spillages, old debris and packaging materials, elimination of sources of infections such as floor cracks and crevices), effective stock control (regular inspection, rotation of stock, early recognition of infestation), optimum storage conditions (maintenance of cool, dry environment) and good packaging (woven sacks and bags, multiply paper sacks stitched at the seams, paper, polythene film, flimsy cardboard are all penetrable by insects and mites) [13]. High temperatures and high humidity could also lead to proliferation of Aspergillus, Fusarium, and Penicillium, the natural fungal flora usually found in the food chain that produce mycotoxins [14]. Mycotoxins are reported such as the major chemical contaminants found in tea products together with pesticides residues and heavy metals. Few reports focused on the mycotoxin detection in tea samples, however aflatoxins, ochratoxin $\mathrm{A}$, and fumonisins were found in black tea samples. Acting such as carcinogenic and teratogenic agents, mycotoxins are recognized as a serious threat to human health [14].

Awareness-raising campaigns among sellers and food quality control authorities should be conducted to improve the quality of food for the Congolese people. 


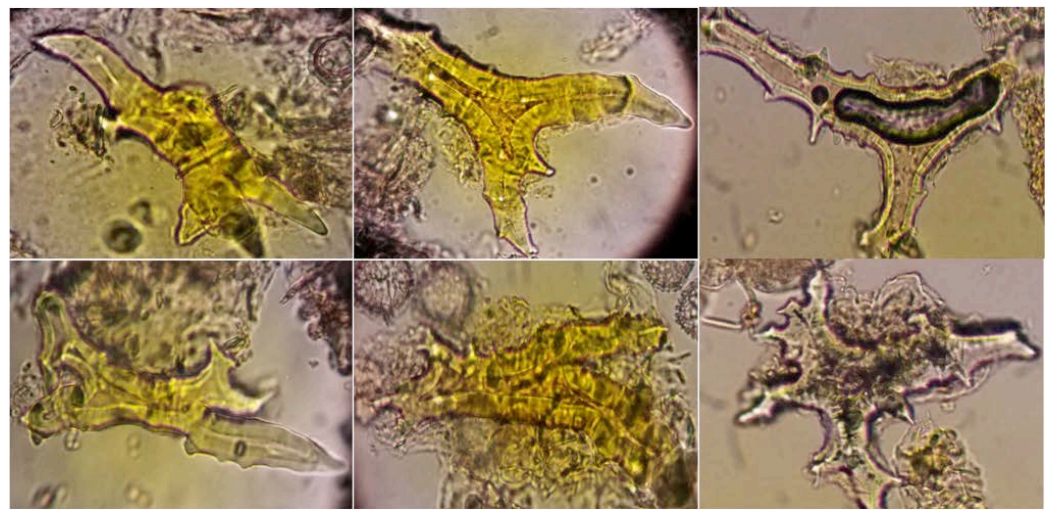

Figure 2. Different types of asterosclerites of tea $(40 \times)$.
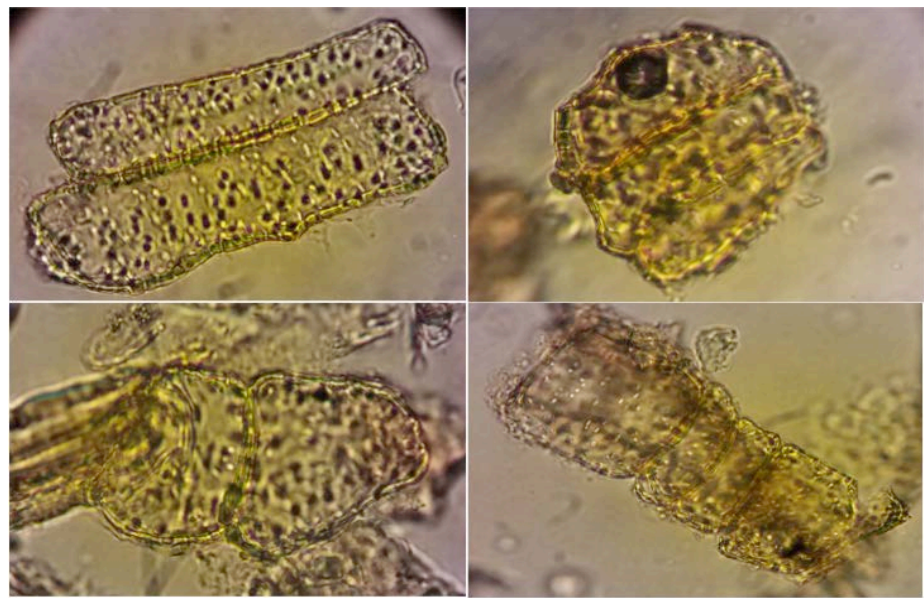

Figure 3. Different grouped sclereids of tea $(40 \times)$.

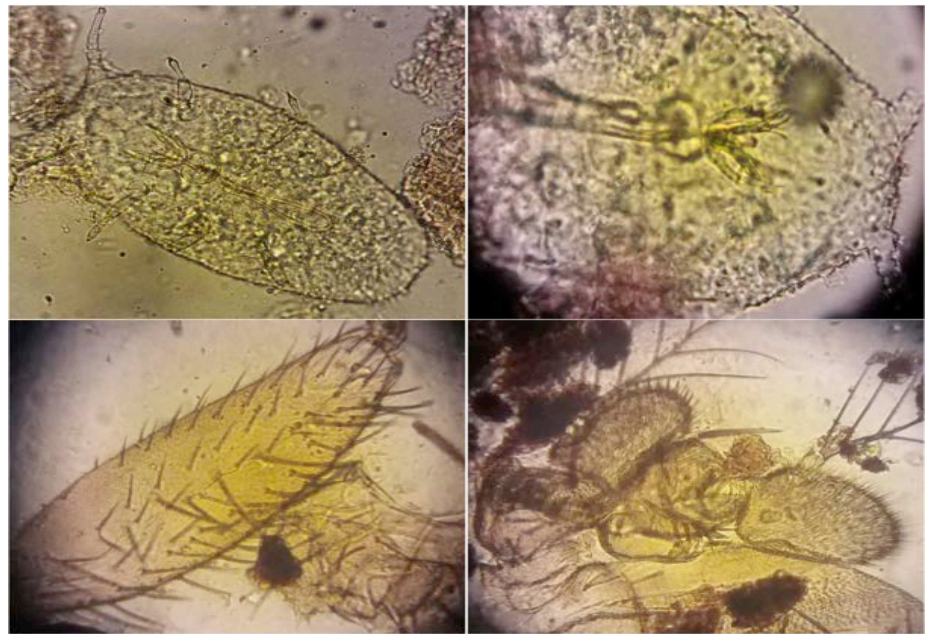

Figure 4. Entire insect pests (mites) and their parts (40×).

\subsection{Phytochemicals}

Phytochemical analysis revealed the presence of anthocyanidins, phenolic acids, flavonoids, iridoids, terpenes. TLC and HPLC fingerprints of all black tea samples were nearly similar and showed the presence of glycosylated flavonoids and 
phenolic acids as main compounds. By comparison with standards, they showed that extracts of teas contain chlorogenic acid, gallic acid, ferulic acid such as phenolic acids and astragalin, hyperoside, kaempferol, quercetin-3-O-rutinoside (rutin) such as flavonoids (Figure 5). HPLC analysis revealed that hyperoside, rutin and kaempferol 3-O-rutinoside was the main glycosylated flavonoids in accordance with previous studies [15]. Hyperoside was the major pic in the all tea HPLC chromatograms (Figure 6).

Previous phytochemical analysis showed that the chemical components of tea leaves include polyphenols, alkaloids (caffeine, theobromine, theophylline, etc.), volatile oils, polysaccharides, amino acids, lipids, vitamins (e.g., vitamin C), inorganic elements (e.g., aluminium, fluorine and manganese), etc. However, the polyphenols are primarily responsible for the beneficial healthful properties of tea [5] [16] [17].

Polyphenol composition of tea varied with the types of teas [16]. The major polyphenolic compounds in green tea are catechins, and in black tea are flavonoids predominantly polymeric of the type theaflavins and thearubigins. Black tea is produced by fermentation, which is in fact an enzymatic oxidation evoked by polyphenol oxidases native to tea leaves. There are two possible ways of processing in order to obtain black tea using "orthodox rollers" or "crush-tear-curl" (CTC) machines. During black tea manufacturing the most considerable changes occur in the content of catechins. A profound loss in catechin content is observed and at the same time new compounds (theaflavins and thearubigins) are formed as a result of enzymatic oxidation [3] [6] [15] [18]. Black tea retains a high number of the antioxidants polyphenols such as flavonoids. Black tea was reported to contain more gallic acid compared to green tea. Green tea contains six primary catechin compounds, namely catechin, gallocatechin, epicatechin, epigallocatechin, epicatechin-3-gallate and epigallocatechin-3-gallate (EGCG) [6] [19]. Black teas consumed in DR Congo seem to be CTC tea such as the cases of many Africa's countries [15].

Results from the quantitative determination of anthocyanins, flavonoids and total phenolic content are summarized in Table 2. Anthocyanin contents were determined as catechin equivalents in grams per 100 grams of dry weight ( $\mathrm{g}$ $\mathrm{CE} / 100 \mathrm{~g} \mathrm{DW}$ ), while total polyphenol contents were calculated as gallic acid equivalents in grams per 100 grams of dry weight (g GAE/100g DW). Flavonoid content was determined as quercetin equivalents in grams per 100 grams of dry weight (g QE/100g DW). The anthocyanin, flavonoid and total phenolic contents varied significantly $(\mathrm{p}<0.05)$ between the studied teas. The tea 1 showed the highest value of total phenol content and anthocyanins, the tea 7 the highest value of flavonoid content.

\subsection{Antioxidant Activity}

Radical scavenging activity of tested infusion extracts of teas, determined by two biochemical in vitro methods namely ABTS and DPPH assays is presented in 
Table 3 and is expressed as $\mathrm{IC}_{50}$ values. $\mathrm{IC}_{50}$ is the amount of antioxidant necessary to decrease the initial concentration of radical by $50 \%$.

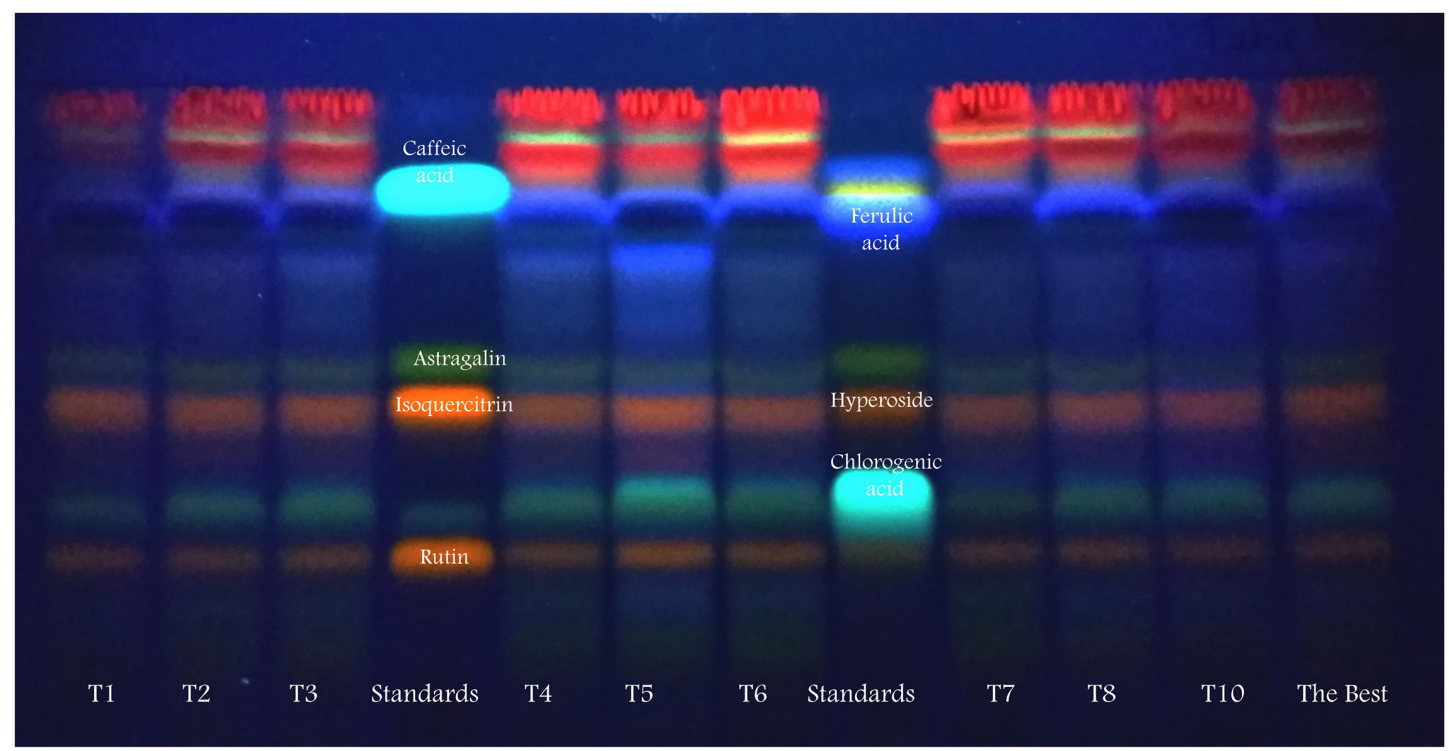

Figure 5. TLC chromatograms of methanolic extracts from Tea samples with caffeic acid, chlorogenic acid, ferulic acid, hyperoside, astragalin, isoquercitrin and rutin as standards; developed with ethyl acetate/formic acid/methanol/water (20:0.5:2.5:2; $\mathrm{v} / \mathrm{v} / \mathrm{v} / \mathrm{v}$ ) and visualized at $365 \mathrm{~nm}$ with Natural Products-PEG reagent. Flavonoids are detected as yellow-orange fluorescent spots and phenolic acids as blue fluorescent spots.

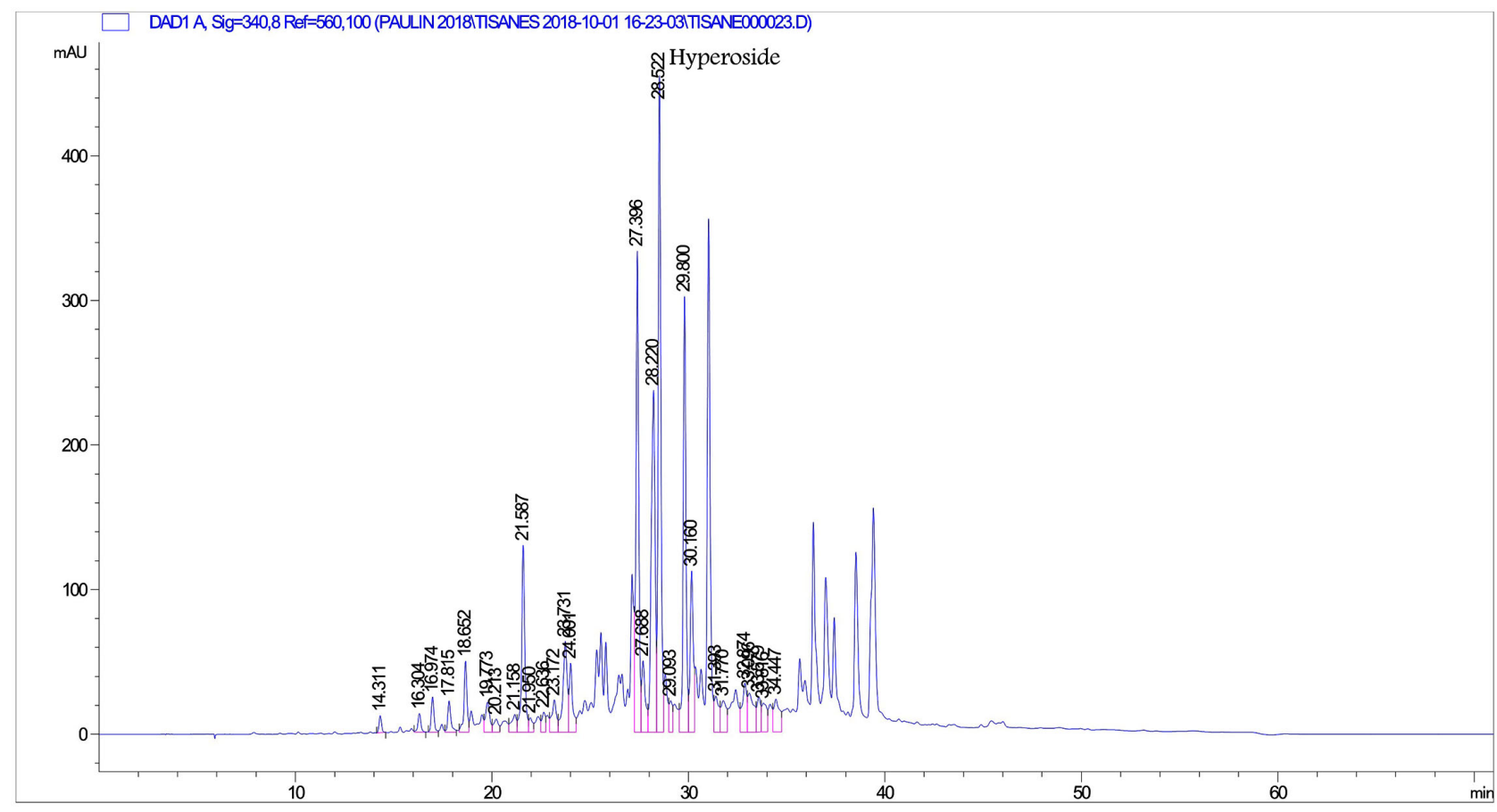

Figure 6. HPLC chromatogram of methanolic extract of black tea using a nonlinear gradient of acetonitrile (A) and $0.05 \%$ trifluoroacetic acid in ultra-pure water (B): $0 \mathrm{~min}, 0: 100$ (A:B), $1 \mathrm{~min}, 3: 97$ (A:B); $45 \mathrm{~min}, 40: 60$ (A:B); $55 \mathrm{~min}, 40: 60$ (A:B); $56 \mathrm{~min}$, 0:100 (A:B) and $60 \mathrm{~min}$, stop at $1 \mathrm{~mL} / \mathrm{min}$ on Hypersil ODS column $(4 \mathrm{~mm} \times 250 \mathrm{~mm})$ with detection at $340 \mathrm{~nm}$. The elution time is given in minutes (horizontal axis). On the y-axis, the height of the elution peak, expressed in arbitrary milli-units (mAU) corresponds to the concentration of the eluted compound in the sample analyzed. 
Table 2. Total anthocyanins, flavonoids and total phenolic contents of selected teas.

\begin{tabular}{cccc}
\hline Samples & $\begin{array}{c}\text { Total Polyphenol Contents } \\
(\mathrm{g} \text { GAE/100g) }\end{array}$ & $\begin{array}{c}\text { Flavonoids } \\
(\mathrm{g} \text { QE/100g) }\end{array}$ & $\begin{array}{c}\text { Anthocyanins } \\
(\mathrm{g} \text { CE/100g) }\end{array}$ \\
\hline Tea 1 & $180.13 \pm 3.22$ & $4.32 \pm 0.04$ & $5.54 \pm 0.42$ \\
Tea 2 & $175.4 \pm 5.13$ & $4.63 \pm 0.2$ & $3.35 \pm 0.1$ \\
Tea 3 & $122.5 \pm 1.88$ & $3.56 \pm 0.3$ & $2.68 \pm 0.44$ \\
Tea 4 & $111.5 \pm 11.97$ & $3.00 \pm 0.2$ & $1.29 \pm 0.53$ \\
Tea 5 & $159.1 \pm 4.5$ & $4.09 \pm 0.56$ & $2.55 \pm 0.44$ \\
Tea 6 & $139.1 \pm 7.56$ & $4.67 \pm 0.05$ & $2.41 \pm 0.21$ \\
Tea 7 & $170.54 \pm 15.26$ & $4.95 \pm 0.4$ & $2.82 \pm 0.21$ \\
Tea 8 & $140.86 \pm 1.8$ & $2.95 \pm 0.14$ & $1.57 \pm 0.36$ \\
Tea 9 & $119.38 \pm 6.61$ & $2.51 \pm 0.07$ & $1.99 \pm 0.9$ \\
Tea 10 & $124.24 \pm 7.5$ & $3.33 \pm 0.3$ & $2.96 \pm 0.24$ \\
Tea TB & $165.24 \pm 7.5$ & $4.31 \pm 0.6$ & $2.01 \pm 0.12$ \\
\hline
\end{tabular}

Table 3. $\mathrm{IC}_{50}$ values $\left(\mu \mathrm{g} \cdot \mathrm{mL}^{-1}\right)$ of infusion extracts of selected teas on ABTS and DPPH assays (Mean $\pm \mathrm{SD}, \mathrm{n}=6$ ).

\begin{tabular}{ccc}
\hline \multirow{2}{*}{ Samples } & \multicolumn{2}{c}{$\mathrm{IC}_{50}\left(\mu \mathrm{g} \cdot \mathrm{mL}^{-1}\right)$} \\
\cline { 2 - 3 } & $7.36 \pm 0.78$ & DPPH \\
\hline Tea 1 & $7.64 \pm 0.65$ & $13.77 \pm 0.77$ \\
Tea 2 & $6.76 \pm 0.49$ & $13.36 \pm 1.17$ \\
Tea 3 & $5.85 \pm 0.57$ & $9.04 \pm 0.93$ \\
Tea 4 & $6.19 \pm 0.62$ & $11.35 \pm 1.02$ \\
Tea 5 & $5.78 \pm 0.37$ & $18.71 \pm 1.41$ \\
Tea 6 & $8.18 \pm 0.68$ & $13.74 \pm 1.15$ \\
Tea 7 & $4.58 \pm 0.3$ & $15.03 \pm 0.97$ \\
Tea 8 & $5.04 \pm 0.46$ & $10.67 \pm 0.76$ \\
Tea 9 & $6.37 \pm 0.69$ & $18.62 \pm 1.83$ \\
Tea 10 & $4.36 \pm 0.44$ & $21.83 \pm 1.55$ \\
TeaTB & $0.71 \pm 0.08$ & $10.94 \pm 0.54$ \\
Gallic acid & & $1.07 \pm 0.10$ \\
\hline
\end{tabular}

Lower $\mathrm{IC}_{50}$ value indicates a higher antioxidant activity. All the extracts had significant scavenging effects with antiradical activities connected to their ability to scavenge free radicals according to their $\mathrm{IC}_{50}$ values. $\mathrm{IC}_{50}$ for infusion extracts showed that Tea 8 and TeaTB are the most active in ABTS assay; while in DPPH assay Tea 3 is the most active, but there is not significative difference with Tea 8 and TeaTB. Our results obtained from ABTS and DPPH assays show that all the infusion extracts of bulk-marketed black teas possessed antioxidant properties comparable to the reference packaged tea (TeaTB). The tea "LEBEST" is the main packaged black tea marketed in DRC. The two-way Anova test showed that there are no statistical differences between TeaTB (The reference tea) and Tea 4 , 6, 8 and 9 in ABTS assay and Tea 1, 2, 3, 4, 6 and 8 in DPPH assay $(\mathrm{p}<0.05)$ (Figure 7 and Figure 8). 
ABTS Antiradical Capacities

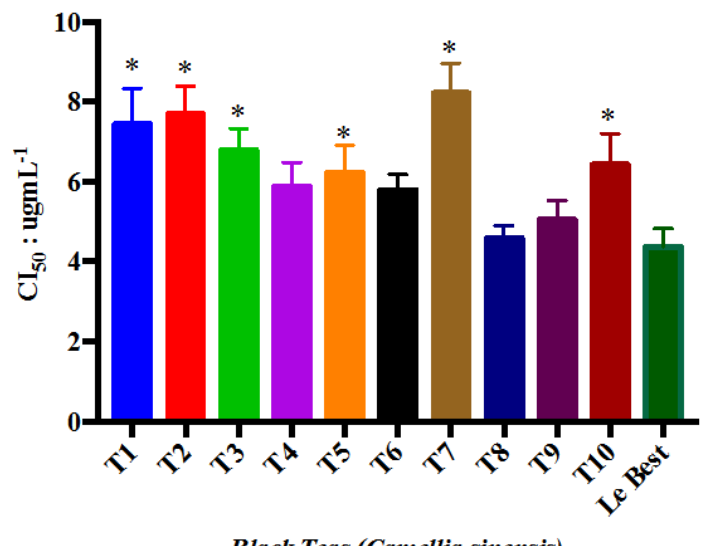

Figure 7. ABTS-radical scavenging activity expressed in $\mathrm{IC}_{50}$ values $\left(\mu \mathrm{g} \cdot \mathrm{mL}^{-1}\right)$. All data are expressed as the means $\pm \mathrm{SD}$. ${ }^{\star} \mathrm{P}<0.05$ indicated a statistically significant difference between Reference black tea (LEBEST) and the bulk-marketed black teas.

DPPH Antiradical Capacities

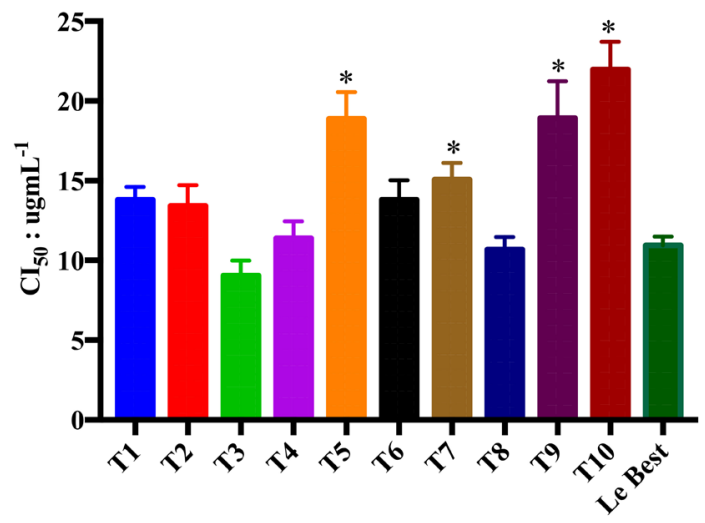

Black Teas (Camellia sinensis)

Figure 8. DPPH-radical scavenging activity expressed in $\mathrm{IC}_{50}$ values $\left(\mu \mathrm{g} \cdot \mathrm{mL}^{-1}\right)$. All data are expressed as the means $\pm \mathrm{SD} .{ }^{\star} \mathrm{P}<0.05$ indicated a statistically significant difference between Reference black tea (LEBEST) and the bulk-marketed black teas.

Our results were correlated between the two chemical methods used. The differences observed between the two methods could be attributed to the fact that DPPH assay only detect hydrophilic antioxidants in the contrary of ABTS assay. The highest radical-scavenging capacities of infusion extracts of studied teas are not in adequacy with their anthocyanin, flavonoid and total phenolic contents. The basic bioactive compounds in tea are polyphenols. Antioxidant potential of studied black teas varied related to their quantity of polyphenol compounds. The antioxidant activity of tea polyphenols is not only due to their ability to scavenge superoxide but also due to increased activity of some detoxifying enzymes such as glutathione peroxidase, glutathione reductase, glutathione-S-transferase, catalase [2] [16]. 


\subsection{Peroxidase Inhibition}

Peroxidases represent a family of isoenzymes actively involved in oxidizing reactive oxygen species, innate immunity, hormone biosynthesis and pathogenesis of several diseases. Even though peroxidases perform a great role in protective mechanisms but still some peroxidases can also lead to some deleterious reactions like co-oxidation of endogenous substrates, drugs and xenobiotics which lead to lipoprotein oxidation, carcinogenesis and liver necrosis. So nowadays even variety of inhibitors are also used against different types of tissue specific peroxidases to treat various types of diseases [20]. Peroxidases generally use $\mathrm{H}_{2} \mathrm{O}_{2}$ as one of the substrates. The MPO is, a pro-oxidant enzyme involved in secondary cell damage. MPO and its metabolites are biomarkers for infectious diseases and a wide array of non-infectious and neurodegenerative disorders [20] [21]. In MPO direct technique, all infusion extracts of teas exhibited a dose-dependent inhibitory effect on MPO activity in the range concentrations of 1 to $20 \mu \mathrm{g} \cdot \mathrm{mL}^{-1}$. This inhibitory effect was significantly higher $(\mathrm{p}<0.0001)$ and showed a better interaction of molecules of tea extracts with the enzyme (Figure 9 ).

Altogether the results showed that the extracts tested showed the highest acellular and the highest inhibition on MPO activity. Phenolic compounds such as catechins, glycosylated flavonoids of tea extracts were reported to be excellent inhibitors of MPO and the pyrogallol group in the B ring, the 3, 4', and 5-OHs, and of the $\mathrm{C} 2-\mathrm{C} 3$ double bond are essential for both binding and reactivity with peroxidase such as MPO [22] [23].

The inhibition of HRP-catalyzed oxidation reactions was studied by using L-012 chemiluminescence method. L-012 is a luminol-based molecule that has been reported to produce much stronger chemiluminescence (CL) than other CL probes [21]. Tea extracts showed a less effective inhibition of HRP oxidant activity and the effect appears at the concentration of $80 \mu \mathrm{g} \cdot \mathrm{mL}^{-1}$. At concentration of $100 \mu \mathrm{g} \cdot \mathrm{mL}^{-1}$, the percentage of inhibition effect was approximatively $50 \%$ for Tea 5, Tea 6, Tea 7, Tea 8 and TeaTB.

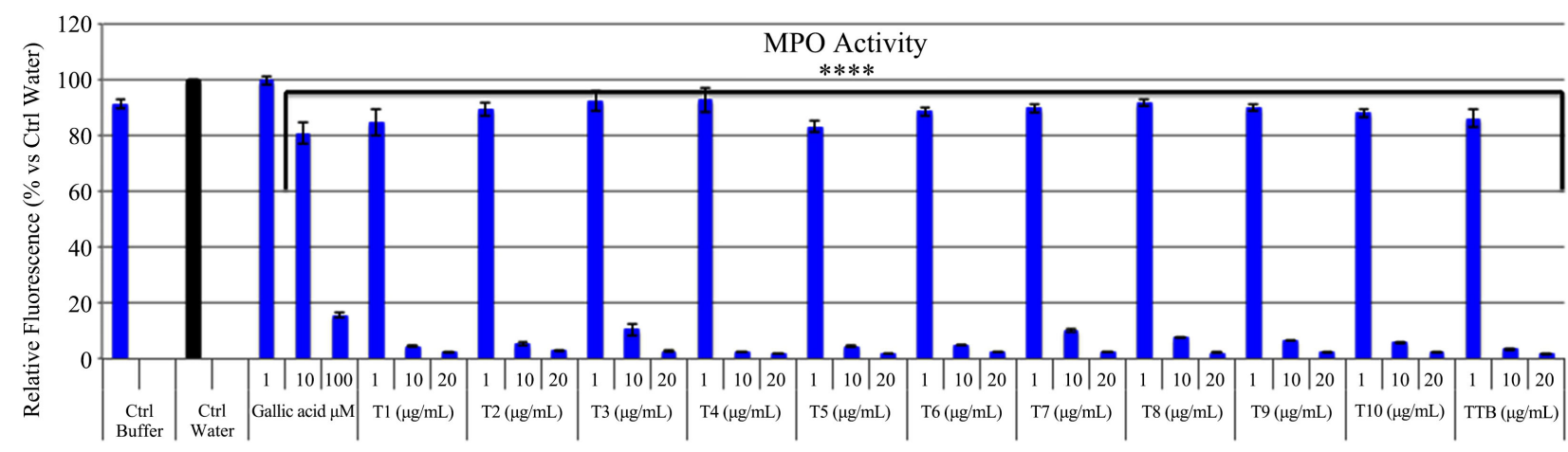

Figure 9. Effect of gallic acid and aqueous extracts from Tea (T: bulk-marketed black tea; TTB: reference packaged tea named LEBEST) on MPO activity. Notes: the percentage of inhibition was calculated for each sample concentration versus the corresponding control (MP0 + Water), taken as $100 \%$ (mean \pm sd, $n=3$ ), samples vs. control Water. $p$-values $(* * *<p 0.0001)$ calculated by two-way ANOVA indicated a significant effect vs. Water control set as $100 \%$ response. ns = not significant vs. Water control. 
Horseradish peroxidase (HRP) was used for the investigation of inhibitor activity of anti-inflammatory drugs [24]. The results of this assay showed that tea extracts exhibited a moderate capacity to inhibit HRP catalytic activity related to their polyphenolic contents. Phenolic compounds contained in tea extracts, should be responsible of exhibited inhibitory properties on HRP. Mahfoudi et al. (2017) reported that flavonoids exhibited a great capacity to inhibit HRP and the presence of 4'-OH groups on the B ring (catechol structure) is most important for this potent peroxidase inhibition [25].

In some acute and chronic pathologies peroxidases generate a battery of highly diffusible reactive oxidants, which instigate oxidative damage in the host tissues at the inflammatory sites exacerbating tissue damage [26]. Our results demonstrated that all extracts from bulk-marketed black teas exerted a noticeable inhibitory effect on the MPO and on HRP catalytic activity comparable to tea "LEBEST", the packaged black tea used such as reference. Obtained results showed that unpackaged black tea marketed, largely consumed by Congolese people would procure the health benefits under different conditions. However, storage conditions must be improved to preserve the nutritional and therapeutic values of tea.

\section{Conclusion}

The microscopic analysis of powders from bulk-marketed black teas from DR Congo allowed the identification of specific microscopical features characteristic to Camellia sinensis and the detection of biological contaminants, in this case, the mites. TLC and HPLC analysis indicated that flavonoids and phenolic acids were major phenolic compounds with other secondary metabolites. Aqueous extracts from all bulk-marketed black teas exhibited good antioxidant activities and inhibitory effect on MPO and HRP activities. Bulk-marketed black teas consumed in DR Congo possess antioxidant and anti-inflammatory properties comparable to packaged black tea largely marketed used as tea reference. However, the in vitro activities should be complemented in the future with in vivo evaluation, which could be valorized bulk-marketed black teas.

\section{Acknowledgements}

The authors are thankful to Laboratory of Pharmacognosy and the Centre for Oxygen Research and Development (C.O.R.D.) of University of Liège (Belgium) and Académie de Recherche et d'Enseignement Supérieur (ARES) for their support in this research project

\section{Conflicts of Interest}

The authors declare no conflicts of interest regarding the publication of this paper.

\section{References}

[1] Reygaert, W.C. (2017) An Update on the Health Benefits of Green Tea. Beverages, 


\section{3, 1-14. https://doi.org/10.3390/beverages3010006}

[2] Cabrera, C., Artacho, R. and Gime, R. (2006) Beneficial Effects of Green Tea-A Review. Journal of the American College of Nutrition, 25, 79-99. https://doi.org/10.1080/07315724.2006.10719518

[3] Bartoszek, M., Polak, J. and Chorążewski, M. (2018) Comparison of Antioxidant Capacities of Different Types of Tea Using the Spectroscopy Methods and Semi-Empirical Mathematical Model. European Food Research Technology, 244, 595-601. https://doi.org/10.1007/s00217-017-2986-Z

[4] Zhao, C., Li, C., Liu, S. and Yang, L. (2014) The Galloyl Catechins Contributing to Main Antioxidant Capacity of Tea Made from Camellia sinensis in China. The Scientific World Journal, 2014, Article ID: 863984.

https://doi.org/10.1155/2014/863984

[5] Bansal, S., Choudhary, S., Sharma, M., Sharad, S., Lohan, S., Bhardwaj, V., Jyoti, S., et al. (2013) Tea: A Native Source of Antimicrobial Agents. Food Research International, 53, 568-584. https://doi.org/10.1016/i.foodres.2013.01.032

[6] Agnieszka Kosinska, W.A. (2014) Antioxidant Capacity of Tea: Effect of Processing and Storage. In: Preedy, V., Ed., Processing and Impact on Antioxidants in Beverages, Elsevier, Amsterdam, 109-120. https://doi.org/10.1016/B978-0-12-404738-9.00012-X

[7] Bahati, L.M., Kapepula, P.M., Kabamba, N.N., Moni, B., Kafuti, G.M., Mungitshi, M., Fundu, T.M., et al. (2017) Microscopic Features, Chromatographic Fingerprints and Antioxidant Property of Some Unconventional Green Leafy Vegetables Consumed in Bandundu, DR Congo. Pharmacognosy Communications, 7, 158-163. https://doi.org/10.5530/pc.2017.4.23

[8] Wagner, H., Bauer, R., Melchart, D., Xioa, P.-G. and Staudinger, A. (2013) Chromatographic Fingerprint Analysis of Herbal Medicinal: Thin-Layer High Performance Liquid Chromatography of Chinese Drugs. Vol. 3, Springer International Publishing, Berlin. https://doi.org/10.1017/CBO9781107415324.004

[9] Kapepula, P.M., Kabamba Ngombe, N., Tshisekedi Tshibangu, P., Tsumbu, C., Franck, T., Mouithys-Mickalad, A., Frédérich, M., et al. (2017) Comparison of Metabolic Profiles and Bioactivities of the Leaves of Three Edible Congolese Hibiscus Species. Natural Product Research, 31, 2885-2892. https://doi.org/10.1080/14786419.2017.1305382

[10] Ngombe, N.K., Ngolo, C.N., Kialengila, D.M., Wamba, A.L., Mungisthi, P.M., Tshibangu, P.T., Kapepula, P.M., et al. (2019) Cellular Antioxidant Activity and Peroxidase Inhibition of Infusions from Different Aerial Parts of Cassia occidentalis. Journal of Biosciences and Medicines, 7, 83-94.

https://doi.org/10.4236/jbm.2019.74009

[11] Kapepula, P.M., Ngumbi, P.B., Kawayidiko, M.K., Mpanzu, A.D., Franck, T., Mouithys-Mickalad, A., Tsobo, C.M., et al. (2018) Anti-Inflammatory and Antioxidant Activities of Rungia congoensis, a Traditional Vegetable Consumed by Yombe People from Kongo Central Area (DR. Congo). Natural Product Research, 33, 1650-1654. https://doi.org/10.1080/14786419.2018.1425847

[12] Franck, T., Mouithys-Mickalad, A., Robert, T., Ghitti, G., Deby-Dupont, G., Neven, P. and Serteyn, D. (2013) Differentiation between Stoichiometric and Anticatalytic Antioxidant Properties of Benzoic Acid Analogues: A Structure/Redox Potential Relationship Study. Chemico-Biological Interactions, 206, 194-203. https://doi.org/10.1016/j.cbi.2013.09.009

[13] Evans, W. (2009) Trease and Evans Pharmacognosy. Elsevier Health Sciences, Lon- 
don, 614.

[14] Sedova, I., Kiseleva, M. and Tutelyan, V. (2018) Determination and Risk Evaluation. Toxins, 10, 444. https://doi.org/10.3390/toxins10110444

[15] Carloni, P., Tiano, L., Padella, L., Bacchetti, T., Customu, C., Kay, A. and Damiani, E. (2012) Antioxidant Activity of White, Green and Black Tea Obtained from the Same Tea Cultivar. Food Research International, 53, 900-908. https://doi.org/10.1016/j.foodres.2012.07.057

[16] Sharangi, A.B. (2009) Medicinal and Therapeutic Potentialities of Tea (Camellia sinensis L.)-A Review. Food Research International, 42, 529-535. https://doi.org/10.1016/j.foodres.2009.01.007

[17] Oliveira, A.P., Guimaraes, A.L., Goncalves de Oliveira-Junior, R., Quintans, J.S.S., Antônio de Medeiros, F., Barbosa-Filho, J.M. and Almeida, J.R.G.S. (2016) Camellia sinensis (L.) Kuntze: A Review of Chemical and Nutraceutical Properties. In: Gupta, V.K., Ed., Natural Products. Research Reviews, Volume 4, Chapter 2, Thomson Press, Haryana, 44.

[18] Peterson, J., Dwyer, J., Bhagwat, S., Haytowitz, D. and Holden, J. (2005) Major Flavonoids in Dry Tea. Journal of Food Composition and Analysis, 18, 487-501. https://doi.org/10.1016/j.jfca.2004.05.006

[19] El-Shahawi, M., Hamza, A., Bahaffi, S.O. and Abduljabbar, T.N. (2012) Analysis of Some Selected Catechins and Caffeine in Green Tea by High Performance Liquid Chromatography. Food Chemistry, 134, 2268-2275. https://doi.org/10.1016/j.foodchem.2012.03.039

[20] Khan, A.A., Rahmani, A.H., Aldebasi, Y.H. and Aly, S.M. (2014) Biochemical and Pathological Studies on Peroxidases-An Updated Review. Global Journal of Health Science, 6, 87-98. https://doi.org/10.5539/gjhs.v6n5p87

[21] Ray, R.S. and Katyal, A. (2016) Myeloperoxidase: Bridging the Gap in Neurodegeneration. Neuroscience and Biobehavioral Reviews, 68, 611-620. https://doi.org/10.1016/j.neubiorev.2016.06.031

[22] Shiba, Y., Kinoshita, T., Chuman, H., Taketani, Y., Takeda, E., Kato, Y., Kawai, Y., et al. (2008) Flavonoids as Substrates and Inhibitors of Myeloperoxidase: Molecular Actions of Aglycone and Metabolites. Chemical Research in Toxicology, 21, 1600-1609. https://doi.org/10.1021/tx8000835

[23] Gau, J., Furtmüller, P.G., Obinger, C., Prévost, M., Van Antwerpen, P., Arnhold, J. and Flemmig, J. (2016) Flavonoids as Promoters of the (pseudo-)halogenating Activity of Lactoperoxidase and Myeloperoxidase. Free Radical Biology and Medicine, 97, 307-319. https://doi.org/10.1016/j.freeradbiomed.2016.06.026

[24] Ostojic, J., Herenda, S., Galijasevic, S., Galic, B. and Milos, M. (2017) Inhibition of Horseradish Peroxidase Activity by Boroxine Derivative, Dipotassium-Trioxohydroxytetrafluorotriborate $\mathrm{K}_{2}\left[\mathrm{~B}_{3} \mathrm{O}_{3} \mathrm{~F}_{4} \mathrm{OH}\right]$. Journal of Chemistry, 2017, Article ID: 8134350. https://doi.org/10.1155/2017/8134350

[25] Mahfoudi, R., Djeridane, A., Benarous, K., Gaydou, E.M. and Yousfi, M. (2017) Structure-Activity Relationships and Molecular Docking of Thirteen Synthesized Flavonoids as Horseradish Peroxidase Inhibitors. Bioorganic Chemistry, 74, 201-211. https://doi.org/10.1016/j.bioorg.2017.08.001

[26] Serteyn, D., Grulke, S., Franck, T., Mouithys-Mickalad, A. and Deby-Dupont, G. (2003) La myéloperoxydase des neutrophiles, une enzyme de défense aux capacités oxydantes. Annales de Medecine Veterinaire, 147, 79-93. 